\title{
Chapter 1 \\ On the Transition Temperature to Calcite and Cell Lengths for Various Biogenic Aragonites
}

\author{
Taiga Okumura, Masahiro Yoshimura, and Toshihiro Kogure
}

\begin{abstract}
In order to understand the mineralogical difference between biogenic aragonites and their geological or synthetic ones, the transition temperature from aragonite to calcite by heating and the cell lengths of a number of biogenic aragonites have been measured using conventional and high-temperature XRD, as well as those of abiotic ones. Among 21 specimens, most biogenic aragonites showed a transition temperature $60-100{ }^{\circ} \mathrm{C}$ lower than that for abiotic ones. However, the shells of land snails showed almost similar transition temperatures. The temperature range from the beginning to the completion of the transition was also varied among the biogenic aragonites. On the other hand, the axial ratios $(a / b$ and $c / b)$ of aragonites in marine molluscan species were considerably larger than those of abiotic ones. However, aragonites in freshwater molluscan species and land snails showed axial ratios similar to abiotic ones. X-ray microanalysis suggested that the origin of such abnormal cell lengths was sodium incorporated in the aragonite crystals, not due to lattice distortion induced by the intracrystalline organic molecules proposed in previous researches.
\end{abstract}

Keywords Aragonite $\cdot$ Calcite $\cdot$ Transition temperature $\cdot$ Cell lengths $\cdot$ Axial ratio - Sodium

\subsection{Introduction}

Aragonite is one of the polymorphs of anhydrous calcium carbonate $\left(\mathrm{CaCO}_{3}\right)$ and thermodynamically slightly less stable than calcite at the ambient temperature and pressure in which organisms are alive. However, aragonite commonly occurs by biomineralization processes. It has been often reported that biominerals possess distinct characteristics and properties which are not observed in their geological or

T. Okumura $\cdot$ M. Yoshimura $\cdot$ T. Kogure $(\bowtie)$

Department of Earth and Planetary Science, The University of Tokyo, Tokyo, Japan

e-mail: okumura@eps.s.u-tokyo.ac.jp; Masahiro.Y@eps.s.u-tokyo.ac.jp;

kogure@eps.s.u-tokyo.ac.jp 
synthetic counterparts. Biogenic aragonite is not the exception. For instance, Koga and Nishikawa (2014) investigated the transition from coral aragonite to calcite by heating in a thermogravimetric (TG)-differential thermal analysis (DTA) apparatus. They found that when the temperature was increased at a certain rate, the temperature at which the aragonite-calcite phase transition occurred was around $100{ }^{\circ} \mathrm{C}$ lower for the coral aragonite than the geological ones. Please note that this temperature is not corresponding to that at which the thermodynamic stability between aragonite and calcite is reversed. They ascribed such a low temperature for the transition to the existence of interstitial water between aragonite crystals, which was released during the transition.

On the other hand, the crystallographic parameters of biominerals have been also reported to be specific, compared to abiotic minerals. Pokroy et al. (2004, 2007) found that the cell lengths of aragonite in the shells of three molluscan species were slightly different from those of abiotic minerals; the $a$ - and $c$-lengths are longer, and the $b$-length is shorter. They suggested that this "distortion" was induced by intracrystalline organic molecules, namely, a biological effect.

These two examples as the specific characters of biogenic aragonite are interesting to consider, for instance, the diagenetic effect on biominerals to form fossils. However, it is not certain whether such characters can be observed ubiquitously in biogenic aragonite formed by other species, families, etc. The present study investigated more than 15 specimens for biogenic aragonite as well as geological and synthetic ones, with respect to their temperatures for aragonite-calcite transition by heating and cell lengths.

\subsection{Materials and Methods}

The aragonite specimens investigated are listed in Table 1.1. In general, all specimens except the synthetic ones were powdered using an agate mortar and pestle for X-ray diffraction (XRD). The two synthetic aragonite specimens (Syn-PVA and Syn-Mg) were prepared according to Kim et al. (2005) and Kitano (1962) using polyvinyl alcohol (PVA) and $\mathrm{MgCl}_{2}$, respectively. In case of multilayered shells with a calcite layer, the calcite layer was removed by grinding with a micro drill, and then the remaining aragonite layer(s) was crushed into powder using an agate mortar and pestle. They were washed with distilled water and ethanol and then dried in an oven.

In the present study, we used an X-ray diffractometer (Rigaku SmartLab) with a high-temperature specimen holder (Rigaku DHS 900), to measure the temperature for the transition from aragonite to calcite. A copper X-ray tube was used and $\mathrm{CuK} \alpha$ was selected by Ni filter. X-ray was detected using a silicon strip detector (Rigaku D/teX Ultra 2). The powdered specimens were processed into a disk of $3 \mathrm{~mm}$ in diameter and $0.5 \mathrm{~mm}$ thick by a press and placed on the high-temperature specimen holder. The temperature was raised at a rate of $5{ }^{\circ} \mathrm{C}$, and $2 \theta$ was scanned repeatedly 
1 On the Transition Temperature to Calcite and Cell Lengths for Various Biogenic...

Table 1.1 Aragonite specimens investigated in this study

\begin{tabular}{|c|c|c|}
\hline \multicolumn{3}{|c|}{ Geological aragonite } \\
\hline Specimen name & Morphology & Occurrence \\
\hline Sefrou, Morocco & Hexagonal prism & Unknown \\
\hline $70087^{\mathrm{a}}$ & Lath & Veins in serpentinite rock \\
\hline $70096^{a}$ & Aciculum & Deposit from hot spring \\
\hline \multicolumn{3}{|c|}{ Synthetic aragonite } \\
\hline Syn-PVA & & Precipitated with PVA \\
\hline Syn-Mg & & Precipitated with $\mathrm{Mg}$ \\
\hline \multicolumn{3}{|c|}{ Molluscan shells (freshwater) } \\
\hline Microstructure & Class & Species \\
\hline \multirow[t]{3}{*}{ Nacre } & \multirow[t]{3}{*}{ Bivalvia } & Anodonta cygnea \\
\hline & & Hyriopsis schlegelii \\
\hline & & Unio douglasiae \\
\hline Prism & Bivalvia & Anodonta cygnea \\
\hline \multicolumn{3}{|l|}{ Otolith } \\
\hline & & Oncorhynchus mykiss \\
\hline \multicolumn{3}{|c|}{ Molluscan shells (terrestrial) } \\
\hline Microstructure & Class & Species \\
\hline \multirow[t]{3}{*}{ Cross-lamellar } & \multirow[t]{3}{*}{ Gastropoda } & Coniglobus mercatorius \\
\hline & & Acusta despecta \\
\hline & & Zaptychopsis buschi \\
\hline \multicolumn{3}{|c|}{ Molluscan shells (brackish water) } \\
\hline Microstructure & Class & Species \\
\hline Cross-lamellar & Gastropoda & Pythia pantherina \\
\hline \multicolumn{3}{|c|}{ Molluscan shells (salt water) } \\
\hline Microstructure & Class & Species \\
\hline \multirow[t]{3}{*}{ Cross-lamellar } & \multirow[t]{3}{*}{ Gastropoda } & Murex pecten \\
\hline & & Acanthopleura japonica \\
\hline & & Lottia dorsuosa \\
\hline \multirow[t]{3}{*}{ Nacre } & Cephalopoda & Nautilus pompilius \\
\hline & Bivalvia & Pinctada fucata \\
\hline & Gastropoda & Haliotis discus \\
\hline
\end{tabular}

\section{Coral}

Galaxea fascicularis

${ }^{\mathrm{a}}$ Collection of The University Museum, The University of Tokyo

from $25.5^{\circ}$ to $30.5^{\circ}$ at a rate of $5^{\circ}(2 \theta) / \mathrm{min}$. One hundred eleven reflection of aragonite and 104 reflection of calcite were recorded in the $2 \theta$ range.

The XRD measurement to refine the cell lengths of aragonite was conducted using a Rint-Ultima ${ }^{+}$diffractometer (Rigaku) with $\mathrm{CuK} \alpha$ radiation monochromated with Ni filter and a silicon strip detector (Rigaku D/teX Ultra 2). The $2 \theta$ range was $10^{\circ}-90^{\circ}$ with continuous scan and a rate of $1^{\circ}(2 \theta) / \mathrm{min}$. Data was collected at every $0.02^{\circ}(2 \theta)$. The powder specimens were mounted in a shallow dimple on a non- 
reflective plate made of silicon. The cell lengths $(a, b$, and $c)$ of aragonite were calculated from the $2 \theta$ values of around 48 reflections, using PDXL software (Rigaku).

Finally, the chemical composition, particularly the concentration of sodium and chlorine, in aragonite was analyzed using an electron-probe microanalyzer (EPMA, JEOL JXA-8530F). The specimens for EPMA were prepared by embedding fragments of the minerals or shells in epoxy resin, polishing with diamond paste and colloidal silica. Finally amorphous carbon was coated by vacuum deposition for electron conductivity.

\subsection{Results and Discussion}

Figure 1.1 represents an example of the high-temperature XRD measurement. The temperature at the right of each pattern indicates the temperature at the beginning of the scanning. Please note that it took only $1 \mathrm{~min}$ for the $2 \theta$ scan, and the rate to increase temperature was $5{ }^{\circ} \mathrm{C} / \mathrm{min}$. The peaks from aragonite were gradually decreased, and conversely 104 peak of calcite was increased, indicating the progress of the phase transition. We estimated by extrapolation the beginning temperature at which 104 peak of calcite had the integrated intensity and the ending temperature at

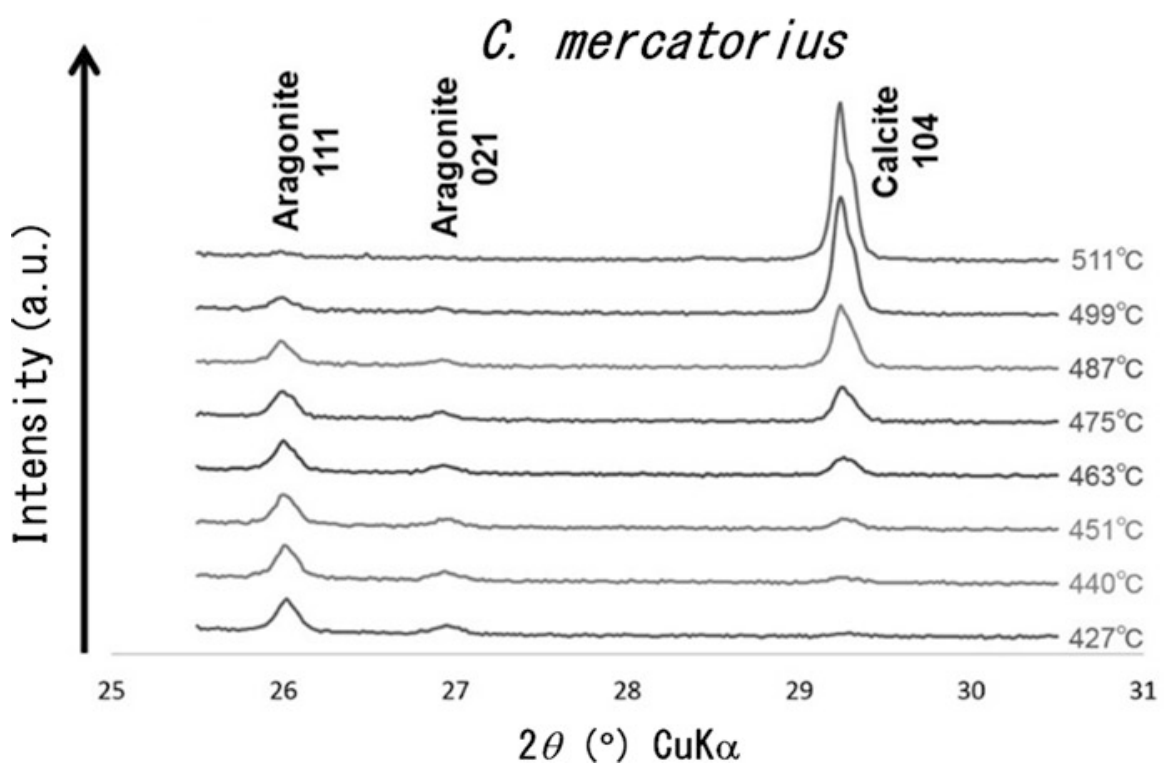

Fig. 1.1 An example of in situ high-temperature XRD pattern to determine the temperature for the aragonite-calcite transition 


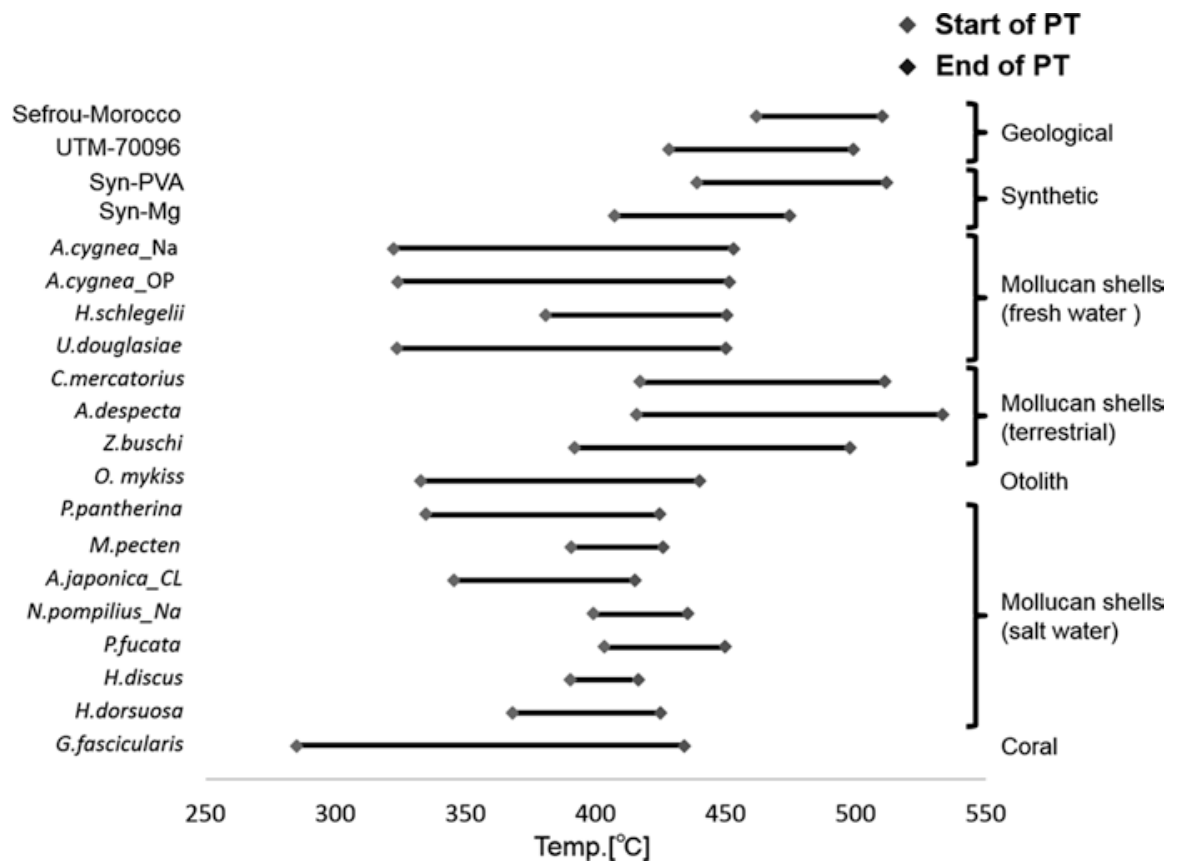

Fig. 1.2 The beginning and ending temperatures of the transition for aragonite specimens of various origins. PT indicates phase transition

which 111 peak of aragonite completely lost the intensity. The two temperatures for all biogenic aragonites of several geological and synthetic aragonites are shown in Fig. 1.2. As reported in the previous work (Koga and Nishikawa 2014), biogenic aragonite showed lower beginning and ending temperatures for the transition than geological and synthetic aragonites. Particularly, the beginning temperature for the coral was extremely low. However, the transition temperatures for terrestrial molluscan shells, or land snails, were similar to those for abiotic aragonite, suggesting that biogenic aragonites are not always less stable than abiogenic ones. The origin of the difference of the temperature for the transition is not clear at present. Koga and Nishikawa (2014) proposed that the origin is intercrystalline water in the coral aragonite because water molecules were detected by mass spectroscopy at the transition. However, this is not convincing because the release of water may not be the origin of the transition but the accompanied phenomenon of the transition. It should be revealed by further investigations in the future.

The cell lengths of most of the samples are shown in Fig. 1.3. In the figure, the cell lengths are expressed with the ratio to those of geological aragonite from Sefrou, Morocco ( $a=4.9629$ (10) $\AA, b=7.9690$ (15) $\AA, c=5.7430$ (11) $\AA$ ), according to Pokroy et al. (2007). As Pokroy et al. (2007) reported, $a$ - and $c$-lengths are considerably larger, and $b$-length is shorter for some aragonites in molluscan shells, 

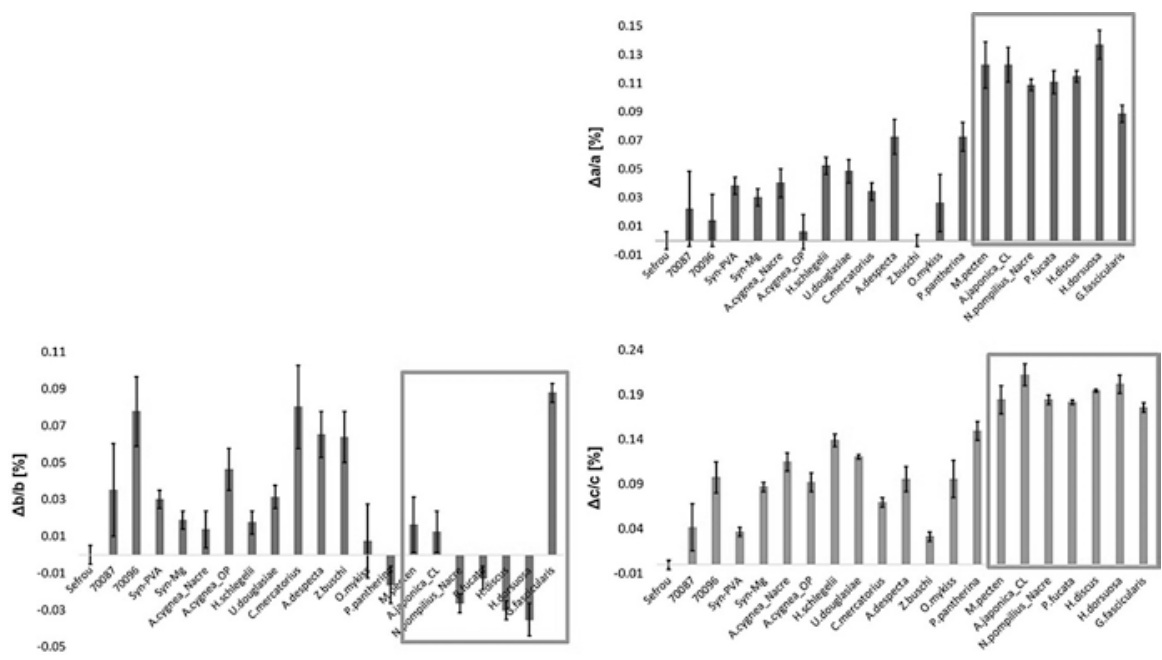

Fig. 1.3 The differences of the cell lengths of various aragonites from that of a geological sample (Sefrou, Morocco). The specimens surrounded with the rectangle are marine molluscan shells and coral

but this trend is not true for all biogenic aragonites. Among all samples investigated, the trend was distinctly observed only for marine molluscan shells. From this result, we supposed that salinity or incorporation of sodium and/or chlorine in the aragonite structure may have resulted in such a systematic change of the cell lengths. Hence, we conducted quantitative analysis of sodium/chlorine concentrations in the samples using EPMA. It was revealed that the content of chlorine was extremely low for all samples and not related to the cell lengths. On the other hand, the concentration of sodium was considerably varied, probably depending on the environments where the aragonites were formed. Considering the origin of the samples, the relationship between the axial ratio $(a / b$ and $c / b)$ and the sodium concentration was summarized as shown in Fig. 1.4. From the figure, it is apparent that distinct cell lengths or anisotropic lattice distortions observed in some biogenic aragonite compared to geological and synthetic ones are originated from the incorporation of sodium in the crystal structure of aragonite. We insist that the abnormality is not owing to intracrystalline organic molecules as proposed in the previous works (Pokroy et al. 2004, 2007).

Pokroy et al. (2004) considered Na-substitution in biogenic aragonite to change the cell lengths, but they denied its possibility because the ionic radii of $\mathrm{Na}^{+}$and $\mathrm{Ca}^{2+}$ are so close that a small substitution of $\mathrm{Na}^{+}$in aragonite cannot change its cell lengths significantly. It is probably true if we suspect only the isomorphic substitution, but the charges of the two cations are different, and some substitution for anions must be accompanied. As stated above, chlorine was not sufficiently detected 


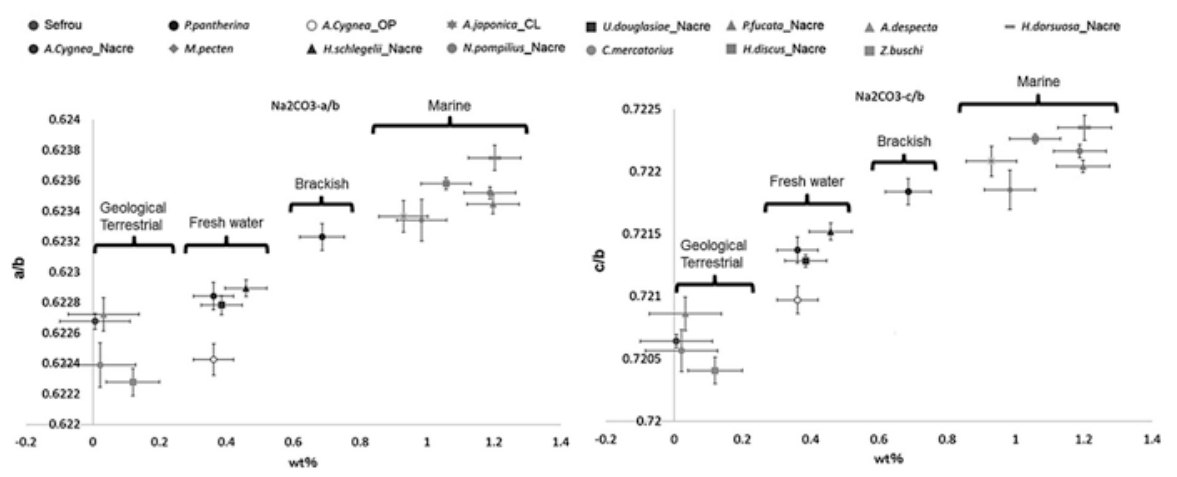

Fig. 1.4 The axial ratios ( $a / b$ in the upper and $c / b$ in the lower figure) vs. concentration of $\mathrm{Na}$ in the aragonites of various origins. The concentration of $\mathrm{Na}$ is expressed as wt. $\%$ of $\mathrm{Na}_{2} \mathrm{CO}_{3}$

in the sodium-bearing aragonites. One possibility is the incorporation of proton or hydroxyl $\left(\mathrm{OH}^{-}\right)$which substitutes $\mathrm{O}^{2-}$ or $\mathrm{HCO}_{3}{ }^{-}$instead of $\mathrm{CO}_{3}{ }^{2-}$. Probably $\mathrm{Na}^{+}$and $\mathrm{OH}^{-}$reside closely in the aragonite structure, and they locally modify the atomic arrangement around the substitution, which may affect the cell lengths. Of course it is not clear why the $a$ - and $c$-lengths were elongated and $b$-length was shrunk by such substitutions, but the idea of intracrystalline organic molecules also cannot explain the anisotropic change. Pokroy et al. (2007) reported that when the biogenic aragonites were heated to $350{ }^{\circ} \mathrm{C}$ in air, the cell lengths became identical to those of geological aragonite, which they proposed the evidence for organic molecules as the origin of the lattice distortion. However, our preliminary experiment revealed that when a marine molluscan shell ( $N$. pompilius) was annealed at around $350{ }^{\circ} \mathrm{C}$, the concentration of sodium was significantly decreased, probably by diffusing away from the aragonite structure. Accordingly, the Na-substitution can also explain the annihilation of abnormality of the cell lengths by heating.

Acknowledgments We are grateful to Prof. A. Checa (Univ. Granada) and Prof. T. Sasaki (Univ. Tokyo) for donating valuable shell samples, Prof. M. Suzuki (Univ. Tokyo) for instructing the preparation of the synthetic aragonite, Mr. K. Fukawa (Univ. Tokyo) for assisting XRD measurement, and Mr. K. Ichimura (Univ. Tokyo) for assisting EPMA analysis.

\section{References}

Kim W, Robertson RE, Zand R (2005) Effects of some nonionic polymeric additives on the crystallization of calcium carbonate. Cryst Growth Des 5:513-522

Kitano Y (1962) The behavior of various inorganic ions in the separation of calcium carbonate from a bicarbonate solution. Chem Soc Jpn 35:1973-1980 
Koga N, Nishikawa K (2014) Mutual relationship between solid-state aragonite-calcite transformation and thermal dehydration of included water in coral aragonite. Cryst Growth Des 14:879-887

Pokroy B, Quintana JP, Caspi EN, Berner A, Zolotoyabko E (2004) Anisotropic lattice distortions in biogenic aragonite. Nat Mater 3:900-902

Pokroy B, Fieramosca JS, Von Dreele RB, Fitch AN, Caspi EN, Zolotoyabko E (2007) Atomic structure of biogenic aragonite. Chem Mater 19:3244-3251

Open Access This chapter is licensed under the terms of the Creative Commons Attribution 4.0 International License (http://creativecommons.org/licenses/by/4.0/), which permits use, sharing, adaptation, distribution and reproduction in any medium or format, as long as you give appropriate credit to the original author(s) and the source, provide a link to the Creative Commons license and indicate if changes were made.

The images or other third party material in this chapter are included in the chapter's Creative Commons license, unless indicated otherwise in a credit line to the material. If material is not included in the chapter's Creative Commons license and your intended use is not permitted by statutory regulation or exceeds the permitted use, you will need to obtain permission directly from the copyright holder.

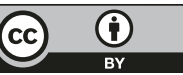

